\title{
Reprodução musical: um diálogo sobre interpretação musical em Schönberg, Kolisch e Adorno
}

\author{
Vinícius Benalia Penteado \\ Universidade de São Paulo, Escola de Comunicações e Artes \\ viniciusbpenteado@usp.br \\ Mário Videira \\ Universidade de São Paulo, Escola de Comunicações e Artes \\ mario.videira@usp.br
}

\begin{abstract}
Resumo: Neste artigo propomos um diálogo entre as teorias de interpretação musical de Arnold Schönberg, Theodor Adorno e Rudolf Kolisch. Nos ensaios de Schönberg, temos os esboços de uma teoria que nunca se completou, assim como nos trabalhos sobre este tema dos outros dois autores aqui mencionados. Assim, o presente trabalho se organiza em três grandes partes: 1) a delimitação histórica do termo reprodução musical; 2) a relação entre o intérprete e a obra, abordando as questões de objetividade e subjetividade; e 3) a perspectiva de uma resolução interpretativa definitiva da obra em questão: a reprodução verdadeira e a morte da obra.
\end{abstract}

Palavras-chave: Schönberg, Kolisch, Adorno, Interpretação Musical, Reprodução Musical.

\section{Musical Reproduction: A Dialogue on Musical Interpretation in Schönberg, Kolisch, and Adorno.}

Abstract: This article proposes a dialogue between the musical interpretation theories of Arnold Schönberg, Theodor Adorno, and Rudolf Kolisch. In Schönberg's essays, we have the outlines of a theory that was never completed, as well as in the works about this theme of the two authors mentioned here. In this way, the present work is organized into three main parts: 1) the historical delimitation of the term musical reproduction; 2) the relationship between the performer and the work, addressing the issues of objectivity and subjectivity; and 3) a perspective of a definitive interpretive resolution of the work in question: the true reproduction and death of the work.

Keywords: Schönberg, Kolisch, Adorno, Musical Interpretation, Musical Reproduction.

\section{Introduçãa ${ }^{1}$}

Este artigo propõe um diálogo entre composição, filosofia e interpretação musical, a partir das formulações e teorias de três figuras centrais para a Segunda Escola de Viena, a saber, o compositor Arnold Schönberg (1874-1951), o filósofo Theodor Adorno (1903-1969) e o violinista Rudolf Kolisch (1896-1978). Schönberg, em seu exílio nos Estados Unidos, escreveu textos e ensaios buscando estabelecer suas diretrizes interpretativas. Neles, o compositor denuncia algumas questões do intérprete moderno, como, por exemplo, a sua supervalorização em detrimento da obra mesma, ou seja, das ideias do compositor nela presentes. Schönberg, então, utiliza o termo "execução musical" para enfatizar a necessidade de realizar o sentido

\footnotetext{
${ }^{1}$ Agradecemos o suporte financeiro através do Processo n ${ }^{\circ}$ 2020/15183-7, Fundação de Amparo à Pesquisa do Estado de São Paulo (FAPESP). “As opiniões, hipóteses e conclusões ou recomendações expressas neste material são de responsabilidade do(s) autor(es) e não necessariamente refletem a visão da FAPESP”.
} 
musical ali estabelecido pelo compositor. Assim, “um bom 'executor' ou 'executante' deve servir à obra e não vice-versa" (KUEHN, 2010, p. 13). Para Schönberg, a obra musical é dotada de propriedades orgânicas, ou seja, não estáticas; sendo assim, pode-se dizer que ela possui uma lógica formal interna, acerca da qual o intérprete deve ter consciência: "Em um sentido estético, o termo forma significa que a peça é 'organizada', isto é, que ela está constituída de elementos que funcionam tal como um organismo vivo" (SCHOENBERG, 1996, p. 27). Portanto, a análise da partitura mostra-se essencial para sua reprodução musical. Veremos como essa perspectiva se desenvolve e se diferencia nas teorias de Kolisch e de Adorno.

Rudolf Kolisch, violinista e líder de grupos camerísticos como o "Quarteto Kolisch"2 e "Quarteto Pro Arte”, foi figura proeminente no debate interpretativo do século XX. Em decorrência da Segunda Guerra, entre 1939 e 1941, Kolisch teve que abandonar suas turnês pela Europa, assumindo a posição de refugiado. Nessa situação e a convite do compositor e amigo Hanns Eisler (1898-1962), o violinista proferiu três cursos na cidade de Nova York que abordavam a problemática do intérprete: "Performance Musical: A Realização do Sentido Musical" (1939), "Como Ensaiar e Tocar Música de Câmara" (1940), e "Workshop para Tocar em Grupo: Pequenas e Grandes Formações ${ }^{3}$. Neles enfatiza como as questões que são abordadas se referem não a problemas específicos de interpretação, mas sim para questões gerais, demonstrando o desejo de Kolisch para estabelecer uma teoria geral de performance musical.

Adorno demonstra interesse por questões interpretativas desde 1925, quando publica o artigo "Zum Problem der Reproduktion" [Acerca do problema da reprodução], na revista musical vienense Pult und Taktstock. Entretanto, o filósofo só retornará ao tema a partir de 1946, quando, após um período de intensa produção ${ }^{4}$, consegue tempo para o estudo de música e piano. Todavia, este projeto sempre se vê interrompido e retomado até o ano de 1959, data de suas últimas anotações sobre este tema. Em 1954, Adorno, Steuermann e Kolisch fazem uma

\footnotetext{
${ }^{2}$ A criação desse quarteto se deu após contato com o Verein für musikalische Privataufführungen de Schönberg, no início dos anos 1920. Além disso, cabe notar que de 1919 a 1921, Rudolf Kolisch foi aluno de composição de Schönberg.

3 "Musical Performance: The Realization of Musical Meaning" (1939); "How to Rehearse and Play Chamber Music" (1940); "Workshop for Ensemble Playing: Small and Large Ensembles" (1941).

${ }^{4}$ Entre os anos 1940-1945, Adorno completa a Dialética do Esclarecimento, a parte da Filosofia da Nova Música dedicada a Schönberg, o livro Composing for the films [Compondo para os filmes], escrito a quatro mãos com Hanns Eisler e boa parte do livro Minima Moralia.
} 
palestra sobre "Nova Música e Interpretação" [New Music and Interpretation]. Em carta para Kolisch, Adorno escreve:

A maneira como pensei sobre o curso é que nós três realmente o daríamos juntos, e que cada um de nós diria algo quando quisesse fazê-lo. [...] A coisa mais importante, eu acho, é deixar claro para os alunos o que realmente é a interpretação estrutural e significativa. Eu havia pensado em dar uma espécie de palestra introdutória com minhas copiosas anotações sobre a teoria da reprodução, que poderíamos então acompanhar na prática. [...] $\mathrm{Na}$ apresentação introdutória, pode-se, acima de tudo, mapear também as zonas de problemas de interpretação e evitar questões unilaterais como a do tempo desde o início ${ }^{5}$ (ADORNO, 2006, p. xiii).

É curioso que nenhum desses três autores chegou a sistematizar e concluir suas teorias sobre interpretação musical. Tudo o que restou foram esboços e transcrições de algumas das palestras proferidas sobre o assunto, a partir das quais podemos deduzir as linhas gerais de suas concepções acerca do tema. O diálogo aqui proposto entre essas teorias busca contribuir para o debate em torno das questões postas pelo problema da interpretação musical.

Desse modo, o artigo é estruturado em três seções que discutem, respectivamente: 1) o contexto histórico e a distinção entre os termos reprodutibilidade técnica e reprodução musical; 2) a relação intérprete-obra (que aborda a maneira pela qual o sentido musical deve ser adquirido e expressado, bem como a inversão da dialética entre essas duas partes); 3) como a reprodução musical verdadeira deve encaminhar a obra para seu fim, para sua resolução definitiva, ou, nas palavras de Adorno, para sua "morte".

$\mathrm{Na}$ primeira parte, situaremos historicamente o debate sobre interpretação musical da primeira metade do século XX. Para tanto, tomaremos como base o ensaio $A$ obra de arte na era da reprodutibilidade técnica (1936), do filósofo Walter Benjamin, com o intuito de apontar as consequências do desenvolvimento da maquinaria industrial na arte. A partir disso, busca-se

\footnotetext{
5 "The way I thought of the course is that we three would really give it together, and that each of us would say something when he saw fit to do so - in the same manner that Horkheimer and I have been holding our seminars together for years, and with great success -. Naturally tempo is only a subsidiary question, and not even the most important one. The most important thing, I would think, is to make it clear to the students what structural and meaningful interpretation actually is. I had thought of giving a sort of introductory lecture from my copious notes on the theory of reproduction, which we could then follow up practically; if you and Eduard do not consider this a good idea, I would be equally happy to begin directly with the practical side. In the introductory presentation, one could above all also map out the zones of interpretation problems, and avoid one-sided questions such as that of tempo from the outset" (ADORNO, 2006, p. xiii).
} 
distinguir o conceito de reprodução musical - adotado tanto por Adorno quanto por Schönberg - do conceito de reprodutibilidade técnica.

Em seguida, faremos uma comparação entre as visões de Kolisch e Schönberg a respeito do papel do intérprete. Se, por um lado, Schönberg ainda defende certa incompreensibilidade de determinados elementos da partitura, Kolisch, por sua vez, irá defender uma concepção de total objetividade do intérprete em relação à partitura. A seu ver, a partitura seria capaz de fornecer todos os elementos necessários para sua interpretação (englobando tanto os aspectos objetivos quanto subjetivos - a expressão). Num texto de Adorno (aliás, bastante admirado por Kolisch $)^{6}$, podemos encontrar a defesa de pontos de vista bastante semelhantes: trata-se do célebre Fragmento sobre música e linguagem (1953). Nele, o filósofo afirma que os sons articulados na música são mais do que “apenas sons”, e dizem algo por trás da camada sensível. Desse modo, a partitura é entendida como um enigma, em que a interpretação objetiva deve comunicar o sentido que fora enclausurado pela notação. Nesta mesma seção, discutiremos a inversão da relação sujeito-objeto, (no caso, intérprete-partitura). Aqui, a obra seria responsável por "dar vida" ao intérprete, excluindo o aspecto subjetivo e individual daquele que a interpreta. Nessa linha, a visão de Kolisch será relacionada à noção adorniana sobre reprodução, "uma imitação de um arquétipo, por mais escondido que possa estar na obra e por mais difícil que seja compreendê-lo", o "raio-x" da obra musical (ADORNO, 2006, p. 183).

Por fim, serão abordadas as consequências de uma "reprodução verdadeira" da obra musical na teoria de Adorno. Para este, existe uma contradição responsável por criar e movimentar a obra. Nesse sentido, a reprodução musical não deve evitar essas contradições afinal, é o desenvolvimento histórico que as engendra -, mas sim desenvolvê-las, pois elas são categorias imanentes da música, que compõem a substância da obra e responsáveis por sua movimentação. Dessa forma, em sua teoria, a verdadeira interpretação deve encaminhar a obra para a sua "morte", pela resolução definitiva das contradições.

\section{Reprodução musical e reprodutibilidade técnica}

A discussão sobre interpretação musical no início do século $\mathrm{XX}$ foi pautada, em grande parte, pelo avanço das ferramentas de reprodução técnica. O campo das ciências humanas foi

\footnotetext{
6 “O ensaio sobre música e linguagem me parece epistemologicamente muito importante. Eu desejaria que você pudesse ocupar-se mais com a Estética” (KOLISCH apud TRIPPETT, 2009, p. 232).
} 
intensamente influenciado pelas consequências do desenvolvimento da maquinaria industrial e da reprodutibilidade técnica.

Um exemplo notável pode ser encontrado no ensaio $A$ obra de arte na era da reprodutibilidade técnica, de Walter Benjamin, que busca elaborar teses sobre o futuro da arte nesse cenário. Como se sabe, o principal conceito empregado por Benjamin neste ensaio é o da aura e, mais precisamente, o momento de sua destruição: o "desencantamento das obras de arte” (BENJAMIN, 2016, p. 187-188), que provocaria uma superação do caráter aurático antes presente. Este conceito pode ser definido da seguinte forma:

Em suma, o que é a aura? É uma teia singular, composta de elementos espaciais e temporais: a aparição única de uma coisa distante, por mais perto que ela esteja. Observar, em repouso, numa tarde de verão, uma cadeia de montanhas no horizonte, ou um galho, que projeta sua sombra sobre nós, significa respirar a aura dessas montanhas, desse galho (BENJAMIN, 2012, p. 184).

A partir disso, Benjamin enxerga um enorme potencial revolucionário, pois a obra destituída desse valor místico - de culto, diria Benjamin -, ou seja, retirada do domínio da tradição, poderia vir a ser desfrutada por qualquer pessoa, de modo a provocar uma mudança drástica na experiência estética dos indivíduos. Este ensaio foi decisivo para Adorno, que o comenta e critica em sua correspondência com o autor. Em carta a Benjamin, de 18.03.1936, Adorno escreve:

Entenda bem: não quero assegurar a autonomia da obra de arte como prerrogativa, e concordo com você que o elemento aurático da obra de arte está em declínio; e não somente, diga-se de passagem, pela reprodutibilidade técnica, mas antes de tudo pelo cumprimento de suas próprias leis formais 'autônomas' (esse é o tema de uma teoria da reprodução musical que eu e Kolisch vimos planejando há anos) (ADORNO, 2012, p. 209).

Embora Adorno concorde com o diagnóstico do fim da aura $^{7}$, ele argumenta que a forma material das obras não é idêntica a esse elemento mágico que se encerra. $\mathrm{O}$ próprio cumprimento das leis formais autônomas seria o responsável pelo desaparecimento aurático; a apreensão profunda de suas regras e atenção minuciosa a elas, provocaria e faria com que o ouvinte se aproximasse do "estado de liberdade".

Desse modo, a "reprodução técnica" de interpretações musicais faria com que a obra musical perdesse muito de seu potencial intratextual. As gravações eliminariam, junto com a aura, o colorido, o contraste e as constituições internas da própria música, resultando em uma

\footnotetext{
${ }^{7}$ Para Araújo (2010, p.131), sob a indústria cultural, "não houve superação da aura pela obra de arte, porque os elementos centrais da aura, autenticidade e unicidade adaptaram-se às mudanças tecnológicas e passaram a constituir elementos essenciais ao modo de produção industrial".
} 
impossibilidade do ouvinte - e também do intérprete - penetrar além do material sensível sonoro. Afinal, usar de "dispositivos mecânicos elimina imediatamente todo problema" (SCHOENBERG, 1984, p. 322).

Por outro lado, a noção de reprodução musical, que Adorno utiliza para tratar da performance, tem incorporada exatamente o que se perde na gravação: a aura, o hic et nunc ${ }^{8}$ da obra de arte. Segundo Kuehn, o termo "reprodução musical" pode ser definido como "a realização sonora de uma obra musical, com base em sua partitura, a qual, por sua vez, representa algo como a 'imagem do som' (KUEHN, 2010, p. 11). Na teoria de Adorno, este conceito envolve os conceitos de interpretação e performance, demonstrando a importância da reprodução musical para poder compreender a parte empírica e teórica das obras musicais em determinado momento histórico. Já a reprodutibilidade técnica, em síntese, refere-se à capacidade de se produzir cópias de um original, aumentando o alcance original do produto terminado.

A concepção de Adorno se situa em uma tradição de pensamento sobre a música que busca desenvolver a maneira pela qual essa reprodução deveria se realizar. Sua teoria é situada da seguinte forma:

\begin{abstract}
1) que a leitura de uma obra musical é uma interpretação; 2) que a interpretação implica certa liberdade, cujos limites de autonomia ainda precisam ser definidos; 3) que o conceito de "reprodução musical" envolve, de maneira indissociável, o intérprete, a obra e sua interpretação; 4) que o executante de uma obra musical é, além de intérprete, um 'imitador' [Nachbildner]; 5) que a reprodução musical proporciona plenitude; e 6) que a reprodução musical envolve também aspectos de integralidade humana, ou seja, questões de ordem ética, política e social. Tudo isso - vale ser reiterado - "como teoria não poderia penetrar o que se funde indissoluvelmente em sua forma" (KUEHN, 2010, p. 11).
\end{abstract}

\title{
Intérprete e obra: objetividade e subjetividade
}

$\mathrm{Na}$ visão de Kolisch, a interpretação musical deve ser a realização direta do conteúdo objetivo fixado na partitura. Desse modo, a admissão de aspectos incompreensíveis na partitura é inadmissível, pois tudo poderia ser decodificado pela interpretação. Aqui, o pensamento musical e o sentido musical são racionalizados na escrita da obra, ou seja, são enclausurados pela notação. Desse modo, Kolisch afirma que a tarefa do intérprete é, "portanto, somente ler o

\footnotetext{
8 "O aqui e agora".
} 
texto $[$ Text $]$ de forma exata e torná-lo audível, 'realizar' [...] os resultados de nossa leitura"9 (KOLISCH, 2009, p. 204). Nessa mesma direção, Schönberg afirma:

O princípio mais elevado de toda a reprodução musical deve ser que aquilo que o compositor escreveu é feito para ser tocado de tal forma que cada nota possa ser escutada nitidamente, e de que todos os sons, sejam eles sucessivos ou simultâneos, estejam em um profundo relacionamento com cada um deles, e que nenhuma parte ofusca a outra, mas, pelo contrário, dá sua contribuição reforçando que todos eles se sobressaem claramente um do outro ${ }^{10}$ (SCHÖNBERG, 1984, p. 319, grifos nossos).

Para Schönberg, o princípio fundamental de qualquer fazer musical é ser capaz de fazer o ouvinte apreender a ideia que o compositor objetivou na partitura, "completo em cada detalhe de conteúdo e construção" (SCHOENBERG, 1984, p. 320). Afinal, em sua perspectiva, as formas, em arte, e especialmente na música, buscam a compreensibilidade. Portanto, resta "organizar essa forma para que ela se torne uma mensagem compreensível 'a quem possa interessar"” (SCHOENBERG, 1984, p. 215).

Adorno, situando-se nessa mesma tradição, afirma que a verdadeira reprodução “é o raio- $x$ da obra', uma metáfora para iluminar clinicamente uma total compreensão da música, tornando a obra visível no mesmo sentido que a nova tecnologia da câmera pode revelar 'o inconsciente óptico""11 (TRIPPETT, 2009, p. 229). Nesse sentido, a "interpretação objetiva" seria aquela capaz de evidenciar todos os aspectos estruturais e coerentes de uma obra, que residiriam por debaixo de "toda superfície sonora sensível", através da articulação mesma do som, relacionando dialeticamente a parte constitutiva e o todo coeso (ADORNO, 2006, p. 1).

Para Kolisch, essa abordagem estritamente racionalista conseguiria evidenciar até mesmo os aspectos expressivos, que não seriam fixados de forma tão objetiva: “o Expressivo poderia,

\footnotetext{
9 "The musical thought is put down, or is 'objectivated' in the text. Our task, thus, would only be to read the text exactly and to make audible, 'to realize', as I call it, the results of our reading" (KOLISCH, 2009, p. 204).

10 "The highest principle for all reproduction of music would have to be that what the composer has written is made to sound in such a way that every note is really heard, and that all the sounds, whether successive or simultaneous, are in such relationship to each other that no part at any moment obscures another, but, on the contrary, makes its contribution towards ensuring that they all stand out clearly from one another" (SCHÖNBERG, 1984 , p. 319, grifos nossos).

11 “Adorno extrapolated that 'die wahre Reproduktion ist die Röntgenphotographie des Werkes,' a metaphor for illuminating clinically a total comprehension of the music, rendering the work visible in the same sense that new camera technology could reveal 'das optische Unbewusste"” (TRIPPETT, 2009, p. 229).
} 
portanto, ser transformado em um elemento performático objetivo" ${ }^{12}$ (KOLISCH, 2009, p. 229).

Schönberg não simpatiza totalmente com essas concepções. Embora afirme que muitos artistas por volta do final do século XIX e início do século XX ultrapassaram os limites de exibição "do poder de emoção que eram capaz de sentir; artistas que consideraram que as obras de arte foram criadas apenas para poderem se expor para o seu público"13; em suma, "que seriam mais importantes do que a obra, do que o compositor" (SCHOENBERG, 1984, p. 319), Schönberg também alerta para o perigo de ambos os extremos. Assim, sobre a teoria de Kolisch, ele diz:

Você acha que saber disso tem alguma utilidade? Não consigo imaginar [...], mas as qualidades estéticas não se revelam a partir daí [...]. Nunca é demais alertar para para que não se superestimem essas análises, pois elas conduzem justamente àquilo contra o que eu sempre combati: ao conhecimento de como [aquilo] é feito. ${ }^{14}$ (SCHÖNBERG apud TRIPPETT, 2009, p. 228).

Schönberg, portanto, assume uma posição que não descarta totalmente o mistério da composição; ele defende que a obra comporia um certo enigma a ser decifrado, e que constituiria parte essencial e indissociável da arte. O intérprete, portanto, estaria em um jogo entre restrição e liberdade, no qual deveria, ao mesmo tempo, enriquecer a composição sem sobrepor sua individualidade à obra.

Acerca disso, Adorno comenta, em seu primeiro artigo ${ }^{15}$ sobre o tema:

De que maneira pode a leitura de uma obra revelar o grau de liberdade que ela proporciona para o intérprete que a executa - isto me parece a tarefa central de uma teoria da reprodução, a qual, entretanto, como teoria, não poderia penetrar o que se funde

\footnotetext{
12 "Espressivo could thus be transformed into an objective performance element" (KOLISCH apud TRIPPET, 2009, p. 229).

13 "It must be admitted that in the period around 1900 many artists overdid themselves in exhibiting the power of the emotion they were capable of feeling; artists who considered works of art to have been created only to secure opportunities for them to expose themselves to their audiences; artists who believed themselves to be more important than the work - or at least than the composer. Nothing can be more wrong then both these extremes" (SCHÖNBERG, 1984, p. 321).

14 “Glaubst Du denn, daß man einen Nutzen davon hat, wenn man das weiß? Ich kann es mir nicht recht vorstellen [...] Aber die ästhetischen Qualitäten erschließen sich von da aus nicht, oder höchstens nebenbei. Ich kann nicht oft genug davor warnen, diese Analysen zu überschätzen, da sie ja doch nur zu dem führen, was ich immer bekämpft habe: zur Erkenntnis, wie es gemacht ist" (SCHÖNBERG apud TRIPPETT, 2009, p. 228).

15 "Zum Problem der Reproduktion" [Acerca do problema da reprodução], na revista musical vienense Pult und Taktstock.
} 
indissoluvelmente em sua configuração e que, em sua plenitude, envolve o imitador como homem íntegro (ADORNO apud KUEHN, 2010, p. 9).

Desse modo, podemos perceber que a teoria de Kolisch pode até mesmo eliminar esse lado da reprodução, provocando uma inversão do papel do intérprete em seu relacionamento com a obra. Aqui, ao invés de produzir subjetividades por meio de seu tocar, a performance articula o "sentido da obra ao invés de enunciar sua fachada tonal, narrando-a subjetivamente" 16 (TRIPPETT, 2009, p. 230). O que está em jogo aqui, portanto, é a capacidade intelectual do intérprete de entender a obra e isso é o que define o "julgamento" da performance: o entendimento correto - ou não - de sua estrutura. Essa distinção se dá entre uma “"bela' performance das coerências superficiais, e uma performance 'objetiva' que articula as relações das partes motívicas e do todo estrutural, tornando audível o processo dialético da integração"17 (TRIPPETT, 2009, p. 230-231). Vejamos agora como o sentido musical é obtido em uma interpretação estritamente objetiva.

\section{Sentido musical na imanência da obra}

Para Kolisch, a análise e a performance da obra efetuadas pelo intérprete devem ter, como fim último, o objetivo de exprimir as ideias musicais fixadas pela notação. Sendo assim, ele faz uma crítica ao ensino musical que delimita como fim último a execução técnica: neste caso, sua tarefa estaria limitada a "construir virtuosos instrumentais e não músicos"18 (KOLISCH, 2009, p. 202). Nesse sentido, o estudo técnico deveria ser apenas um meio para a expressão de seu sentido estritamente musical.

É importante ressaltar que Kolisch (tal como Adorno), tem em mente sobretudo a interpretação de obras autônomas. Ou seja: os problemas da interpretação são aqui direcionados à obra que expressa apenas seu conteúdo apenas por meios musicais (KOLISCH, 2009, p. 203).

\footnotetext{
16 "Adorno and, by implication, Kolisch too, invert this idea, refashioning a performer as one who, in the act of performance, articulates the meaning of a work rather than enunciating its tonal façade, narrating it subjectively" (TRIPPETT, 2009, p. 230).

17 "In the Hegelian tones of Adorno's Theorie this distinction can be characterized as that between a 'beautiful' performance of superficial surface coherences, and an "objective" performance that articulates the relations of motivic part and structural whole, making audible the dialectical process of integration" (TRIPPETT, 2009, p. 230-231).

18 "The general aim is to build up instrumental virtuosos and not musicians" (KOLISCH, 2009, p. 202).
} 
Portanto, em sua visão, a música deve ser concebida a partir da ideia de construção $^{19}$ e não dos "efeitos de sua execução".

Ao tratar da expressão de um sentido musical fixado pela notação, Kolisch não se refere a nenhum tipo de conteúdo extramusical, mas a algo só poderia ser dito através da música: "Música não significa nada mais do que música. É uma linguagem própria"20 (KOLISCH, 2009, p. 203). Em síntese, para a expressão do sentido musical, o músico deve interpretar a partitura. Desse modo, Kolisch afirma:

Nós temos que decidir se algo como a interpretação correta realmente existe! Em outras palavras, seriam as indicações fornecidas pela partitura suficientemente precisas para garantir um 'correto'; ou seja, uma única interpretação? Minha resposta é SIM"21 (KOLISCH, 2009, p. 205).

Como se vê, Kolisch defende enfaticamente a existência de uma interpretação correta e, portanto, objetiva da obra musical. Por outro lado, aquilo que seria uma interpretação subjetiva - que usa "categorias como sentir, instinto, gosto, sentimento" - é excluída da sua teoria, pois transformaria a performance em uma expressão da personalidade do intérprete, ao invés de buscar realizar "os conteúdos objetivos do texto"22 (KOLISCH, 2009, p. 205).

A noção de expressão musical é entendida por Kolisch como sendo a elaboração dos elementos musicais no interior mesmo da obra. Desse modo, cada fenômeno contido na peça deve exercer uma função para que seja possível compreender o pensamento que o compositor racionalizou na partitura (KOLISCH, 2009, p. 206). E isso só se efetuará por meio de uma análise rigorosa da formação musical, podendo assim apreender sua função e seu sentido.

\footnotetext{
19 "Descobrimos que um insight sobre as relações estruturais do trabalho a ser executado é necessário para o propósito de uma apresentação correspondente. É claro que isso só pode ser adquirido por meio de um processo intelectual, que geralmente é conhecido como 'análise'. A forma convencional dessa análise, que determina apenas as partes principais da estrutura tectônica, está longe de ser suficiente para nosso propósito. Temos que traçar a construção até o último detalhe e realmente entender o trabalho de composição. Em muitos casos, este método é acusado de intelectualismo 'e a produção musical espontânea do chamado músico puro-sangue' é levantada contra ele" (KOLISCH apud TRIPPET, 2009, p. 231).

20 "Music does not mean anything else but music. It is a language of its own" (KOLISCH, 2009, p. 202).

21 "Before we answer this question, we have to decide whether such a thing as right interpretation exists at all! In other words, are the indications given through a score precise enough to guarantee a right; that means, only one interpretation? My answer is, YES" (KOLISCH, 2009, p. 202).

22 "You will easily admit that with these personal, private elements as the basis of interpretation, the performance would become an expression of the performer's personality rather than the realization of the objective contents of the text. And it is our aim to make the performance just that" (KOLISCH, 2009, p. 202).
} 
Seguindo nessa linha, seria possível afirmar que "interpretar" um compositor significaria "aprender a ler o seu texto", utilizando somente elementos musicais.

Isso nos leva a um ensaio de Adorno bastante apreciado por Kolisch, o Fragmento sobre música e linguagem, escrito em 1953. Nele, Adorno afirma que a música "assemelha-se à linguagem por ser uma sequência de sons articulados no tempo, sons que são mais do que apenas sons" (ADORNO, 2018, p. 35). Nesse texto ${ }^{23}$, o filósofo defende a ideia de uma linguagem autêntica que pode ser "imaginada por algo humano que não é linguagem, a saber, a música" (MARTINSON, 2018, p. 212). Para o filósofo, "interpretar uma linguagem significa entender a linguagem; interpretar música significa fazer música". Assim, a interpretação musical poderia ser definida como "a execução que, como síntese, estabelece uma semelhança geral com a linguagem, mas que, ao mesmo tempo, liquida toda semelhança com a linguagem" (ADORNO, 2018, p. 38).

Nesse sentido, a diferenciação, para Kolisch, entre um discurso não-musical e um discurso musical seria que este último conseguiria apreender o sentido presente na notação. Desse modo, a partitura configura um enigma cujas chaves para sua solução já foram postas, restando para a interpretação objetiva trazer à baila o sentido que fora enclausurado pela notação empreendida. Em outras palavras, a partitura "deseja comunicar um sentido particular subcutâneo"24 (TRIPPETT, 2009, p. 233). Essa tarefa não é simples, já que existem "poucas pessoas que são capazes de entender, puramente em termos de música, o que a música tem a dizer" ${ }^{25}$ (SCHOENBERG, 1984, p. 141).

A tarefa do intérprete sendo suscetível a uma interpretação "correta" implica no fato de que esse objetivo é finito: seu fim (e sua finalidade) baseia-se tão somente em realizar a obra a partir de seu texto prescritivo. Nesse sentido a partitura é mais uma "equação críptica que,

\footnotetext{
${ }^{23}$ A concepção musical de Adorno, especialmente em suas relações com a linguagem, possui um substrato teológico que se fundamenta em um texto de Walter Benjamin, o ensaio Sobre a Linguagem em Geral e a Linguagem dos Homens, escrito em 1916. No ensaio benjaminiano, o filósofo define que "toda comunicação de conteúdos espirituais [geistigen Inhalt] é língua, linguagem, sendo a comunicação pela palavra apenas um caso particular: o da comunicação humana.” (BENJAMIN, 2011, p. 50).

24 "We may say that, in Kolisch's theory of performance, music constantly aspires to the condition of poetry in that it desires to communicate a particular subcutaneous meaning" (TRIPPETT, 2009, p. 233).

25 "There are relatively few people who are capable of understanding, purely in terms of music, what music has to say" (SCHOENBERG, 1984, p. 141).
} 
quando resolvida ou performada propriamente, produz um produto definitivo" 26 (TRIPPETT, 2009, p. 233).

\title{
Inversão da relação sujeito-objeto na interpretação
}

Esse modo de relação com a partitura faria com que a energia da interpretação fosse realizada mediante um "avivamento", um "ativar" que a obra produziria no intérprete. Nessa linha, afirma Trippett:

\begin{abstract}
Se, como Adorno afirma, a verdadeira reprodução é um raio-x animado de uma obra, o intérprete se torna artificialmente [unnaturally] vivo [...]. Essa perspectiva na verdade inverte a relação sujeito-objeto assumida entre o intérprete e a obra musical. O que se teve, rapidamente, foi uma inversão do agente no palco: ao invés de um intérprete vivo animando uma obra abstrata e, de outra forma, inanimada, nós temos uma obra orgânica que anima - quer dizer, "dá vida ao" - intérprete (cuja subjetividade é negada), mas apenas de acordo com sua configuração objetiva, prescritiva $^{27}$ (TRIPPETT, 2009, p. 234).
\end{abstract}

Aqui fica clara a ideia de que a obra não seria estática, mas possuiria, em seu cerne, um movimento histórico que provocaria mudanças constitutivas. Essa noção é essencial para a teoria sobre reprodução musical de Adorno. Para tanto, voltemos à relação entre música, linguagem e partitura, pois é de suma importância ter em mente que a própria escrita musical enfaticamente falsifica "a noção de que música é intrinsecamente uma linguagem"28 (ADORNO, 2006, p. 187).

Em seu esboço sobre a teoria da reprodução, Adorno distingue a maneira como as palavras se comportam no sistema escrito tradicional: o símbolo (casa, árvore) se afasta cada vez mais do som; o objeto é representado pelo desenho e tem retirado de si sua qualidade temporal, ou seja, é fixado numa atemporalidade sempre acessível. A grafia da palavra se refere ao sentido, ao objeto na forma conceitual, e não ao som que ela pode produzir. Já a grafia da partitura, pelo contrário, não faz sentido sem o som. Nela existe, portanto, uma contradição

\footnotetext{
26 "This autonomous text in turn becomes less a script as the basis for performance and more a cryptic equation that, when solved or performed properly, produces a definite product" (TRIPPETT, 2009, p. 233).

27 "If, as Adorno asserts, true reproduction is an animate x-ray of a work, the performer becomes unnaturally alive, so to speak, and a continuum between man and machine rises in our imagination. This perspective actually inverts the assumed subject-object relationship between a performer and a musical work. There has, in short, been a reversal of agency on stage: rather than a living performer breathing life into the abstract and otherwise inanimate work, we have an organic work that animates - i.e., "gives life to" - the performer (whose subjectivity is negated), but only according to its objective, prescriptive configuration" (TRIPPETT, 2009, p. 234).

28 "Musical writing emphatically falsifies the very thing through which the cultivated philistine's talk of a "tone language' asserts its self-importance: the notion that music is intrinsically a language" (ADORNO, 2006, p. 187).
} 
inerente, a saber: a de atribuir um símbolo linguístico para algo sem língua, conferir sentido para algo sem sentido. Como bem afirmava Schönberg, "os relacionamentos sonoros estabelecidos pela notação precisam de interpretação. Sem interpretação, eles não são compreendidos" 29 (SCHOENBERG, 1984, p. 327). Sendo assim,

[...] na verdade, o paradoxo de objetificar o absolutamente não-objeto em si, embora sem, como linguagem, ser feito para relembrar o objetivo, dita a insuficiência da escrita musical, que, como uma ferida, atesta para a violência experienciada pelo impulso - que de toda forma que ainda sobrevive - pela sua interconexão inalienável pelo processo civilizatório. A escrita musical é um sistema de símbolos fixados para algo que é por sua própria natureza infixável, que só é conservado como um antídoto para a fixação do mundo ${ }^{30}$ (ADORNO, 2006, p. 188).

Ora, a fixação de algo que não é fixável por essência promove a movimentação constitutiva das partituras com o tempo. O aspecto violento mencionado por Adorno, que torna a música reificada contra seu próprio impulso, promove, aos seus olhos, essa contradição fundamental. Percebe-se, desse modo, que o conteúdo imanente da música está sempre em movimento. Nesse sentido, decifrar um tema é compreender o sentido que foi enclausurado historicamente naquele particular. Por outro lado, a totalidade da obra só se revela enquanto construção quando confrontada historicamente. É apenas pelo entendimento [insight] de todas essas partes que o desenrolar objetivo e histórico da obra toma frente. Assim, cria-se na música ${ }^{31}$ (ADORNO, 2006, p. 189). Isso, para Adorno, define a dialética da expressão e construção. Nesse sentido, ele afirma:

Música, como aquilo que é significado e apresentado, vive em si mesma, pois é um movimento de mudança motivado pela história: e justamente como o impulso mimético em si precede individuação, esse movimento sempre se mantém como um movimento coletivo, mesmo onde aparece como um movimento de expressão subjetiva; e a imagem gestual da música se refere, como imagens sociais, não simplesmente para a experiência humana individual que as registra, mas sim para a

\footnotetext{
29 "The sound-relationships established by means of notation need interpreting. Without interpretation they are not understood" (SCHOENBERG, 1984, p. 327).

30 "This contradiction - dictated by the matter itself - of being the language symbol for something alingual, the carrier of meaning for something aconceptual, so in truth the paradox of objectifying the absolute non-object itself, yet without, as in language, being made to resemble the objective, dictates the insufficiency of musical writing, which, like a wound, testifies to the violence experienced by the - nonetheless surviving - impulse through its inalienable entwinement in the civilizatory process. Musical writing is a system of fixed symbols for something by its own nature unfixed, which is only conserved at all as an antidote to the fixing of the world" (ADORNO, 2006, p. 188).

31 "The fact that the signs must be transformed into imitation and the image into insight, as both elements are so closely interwoven that neither is purely given, and that musical writing therefore knows neither pure images nor pure meanings, forces - because of the different natures of images and music - a process of questioning that transforms the musical text into a scene of historical dynamics" (ADORNO, 2006, p. 189).
} 
totalidade social e portanto o processo histórico constitutivo ${ }^{32}$ (ADORNO, 2006, p. 189).

Retomando a ideia apresentada anteriormente, percebe-se que o intérprete está em meio a um jogo entre liberdade e restrição: liberdade, pois a obra nunca havia se apresentado daquela forma, sua configuração é historicamente contingenciada; restrição, pois a partitura, não sendo estática, força o intérprete a tentar esclarecê-la, lutando contra suas características enigmáticas, de difícil elucidação. E tais características não se perdem com a notação cada vez mais precisa dos elementos musicais, pois, quanto "mais exatas as indicações de performance se tornam, mais imperfeitas [elas são]" (SCHOENBERG, 1984, p. 319). Portanto, a interpretação se mostra necessária para "conectar o vão entre as ideias do autor e o ouvido contemporâneo, os poderes assimilativos do ouvinte no tempo em questão"33 (SCHOENBERG, 1984, p. 328).

\section{Reprodução verdadeira e o fim da obra}

Na teoria de Adorno essa zona de indeterminação da obra não é um absoluto. A questão da interpretação como um problema a ser resolvido sobre a escrita musical significa o objetivo do intérprete. E isso pode ser resolvido somente a partir de uma imersão na obra, transformando sua indeterminação em uma objetividade que é legitimada pela própria constituição da partitura. Portanto, ela "é duas coisas ao mesmo tempo: um enigma fundamentalmente insolúvel e o princípio para sua solução"34 (ADORNO, 2006, p. 182)

Desse modo, Adorno define a interpretação como "uma imitação de um arquétipo, por mais escondido que possa estar na obra, e por mais difícil que seja compreendê-lo. A ideia de reprodução musical é a cópia de um original inexistente" 35 (ADORNO, 2006, p. 183, grifos nossos). Portanto, Adorno entende a tarefa do reprodutor musical como sendo a de liquidar a intenção do texto a partir de uma análise pormenorizada na imanência dos símbolos musicais e

\footnotetext{
32 "Music, as that which is signified and depicted, lives within itself, for it is the changing movement motivated by history: and just as the mimetic impulse itself precedes individuation, this movement always remains a collective one, even where it appears as a movement of subjective expression; and the gestural images of music refer, as societal images, not simply to the individual human experience that registers them, but rather to the societal totality and thus the constitutive historical process" (ADORNO, 2006, p. 189).

33 Interpretation is necessary, to bridge the gap between the author's idea and the contemporary ear, the assimilative powers of the listener at the time in question" (SCHOENBERG, 1984, p. 328).

34 "Every musical text is both things at once: a fundamentally insoluble riddle and the principle for its solution" (ADORNO, 2006, p. 182).

35 "Music, however, is indeed made, because it is imitated, and musical experience, if uncorrupted by idealism, knows only too well what is important in singing and playing: not interpretation as an end in itself, but rather the imitation of an archetype, however hidden in the work and however difficult to comprehend it may be. The idea of musical reproduction is the copy of a non-existent original" (ADORNO, 2006, p. 183).
} 
posteriormente "sublimá-los" na reconstituição do original virtual que é imitado nesse processo. Assim, para Adorno (2006, p. 176), a interpretação deveria enfrentar esse paradoxo da escrita musical, ou seja, decifrar a "imagem visualmente solidificada do gesto musical" que foi convertida em uma "genuína concretude musical, onde o impulso mimético sobrevive", a saber: a partitura.

A verdadeira interpretação é um entendimento profundo na imanência da obra mesma, é uma relação com o objeto estético em si. $\mathrm{O}$ "entendimento é nada menos do que uma imersão crítica no texto mesmo, cuja expectativa é encontrar um contexto significativo"36 (ADORNO, 2006, p. 205). Isso leva Adorno a explicitar o problema do sentido musical. Este não se dá a partir dos símbolos presentes na partitura mesma, mas na imersão completa em seu contexto, na consciência de suas relações, pelo "entendimento no interior da estrutura do fenômeno em si" (ADORNO, 2006, p. 206). Por isso a interpretação é o "raio-x" da obra musical. Retomando o conceito já apresentado anteriormente, ela deve libertar o gesto enclausurado no símbolo mediante a conscientização do contexto que o fenômeno sonoro produz. Isso leva o filósofo a afirmar que o "sentido musical como contexto é nada menos do que a totalidade do gesto" (ADORNO, 2006, p. 206).

Dessa forma, torna-se manifesta novamente a contradição que movimenta a obra:

Ao mesmo tempo, reconhecidamente, é esse mesmo aspecto que - como um aumento da conhecimento interpretativo - inaugura a destruição da obra, no sentido de que a contradição entre o contexto e o fenômeno não é externa a ela, mas sim constitui sua força vital; e a qual, se essa contradição não mais existisse, se a obra um dia aparecer em uma forma sensível absolutamente apropriada, lhe será concedida uma qualidade nua, morta e reificada mais uma vez, reproduzindo em um nível mais alto a reificação do realizar obstinado "faça o que está escrito"37 (ADORNO, 2006, p. 209).

A reprodução musical não deve evitar esse processo, pois afinal é o desenvolvimento histórico que a engendra, mas sim ter em mente de que as próprias categorias descritas, que

\footnotetext{
36 "Insight, rather, is nothing other than a critical immersion in the text itself, one whose only expectation is to find a meaningful context" (ADORNO, 2006, p. 205)

37 "At the same time, admittedly, it is also this aspect which - as an increase in the awareness of interpretation inaugurates the work's destruction, in the sense that the contradiction between context and phenomenon is not external to it, but rather constitutes its life-force; and which, if that contradiction should no longer exist, i.e. if the older work should one day appear in a form that is sensually absolutely appropriate, will bestow upon it precisely thus a bare, dead, reified quality once again, reproducing at a higher level the reification of stubbornly realizing 'what is written'. It would be a futile undertaking, however, if, out of fear of what progress might do to the work in the realization of the context through the phenomenon, one sought to prevent it; for precisely the work itself has its substance in such movement, and lacks any substratum that could serve to oppose its immanent movement. It is the innermost nature of true interpretation to contribute to the death of its object" (ADORNO, 2006, p.209-210).
} 
compõem a substância da obra em si, movimentam essa obra. É por esse motivo que Adorno defende que "a natureza mais íntima da verdadeira interpretação é a de contribuir para a morte de seu objeto" (ADORNO, 2006, p. 210).

\section{Conclusão}

A parte interpretativa das obras musicais mostra-se extremamente complexa, abrangendo elementos de difícil compreensão e maturação, tal como pudemos observar nos ensaios e fragmentos de Schönberg, Kolisch e Adorno a respeito do tema.

Opondo-se a Schönberg, o violinista Rudolf Kolisch faz a defesa de uma interpretação musical estritamente objetiva. A seu ver, tanto aspectos objetivos quanto subjetivos (ou seja, expressivos) teriam suas condições dadas pelos elementos musicais reificados na partitura. Por outro lado, Schönberg defende ainda a posição de que existem elementos enigmáticos a serem confrontados pelo futuro intérprete, reivindicando uma zona de indeterminação (e, portanto, de liberdade). Adorno, a partir de seu Fragmento sobre música e linguagem (1953), procura acentuar o modo pelo qual o sentido musical é apreendido pela própria música. Nessa perspectiva, os elementos extramusicais seriam um empecilho na tentativa de se compreender a música. Assim, a diferença entre um discurso musical e um discurso não musical residiria somente na consciência desses elementos presentes na composição. Desse modo, seria viável exigir uma "interpretação correta" da obra musical, sendo ela o único critério possível para se avaliar o resultado de uma reprodução. A noção proposta por Kolisch inverte a relação entre o músico e a obra. Esta última forneceria a "energia" para exigir uma nova reprodução musical, em decorrência da sua não estaticidade, ou seja, da modificação constituinte que a história provoca no interior da obra musical.

De acordo com a concepção adorniana, essa constante movimentação que decorre da relação entre a partitura e a música, acaba por provocar uma contradição fundamental, a saber, o fixar de algo que não é fixável. Todavia, vimos que essa contradição não deve ser evitada, mas tornada consciente, a fim de desenvolvê-la para um outro estágio mais definitivo. Mediante essa ideia, Adorno consegue enxergar a possibilidade do fim da obra, do fim da contradição que a engendra e, logo, da sua necessidade de existir. Sendo assim, a reprodução musical verdadeira deve buscar resolver os problemas com os quais se confronta e que a estimulam. Vale lembrar que para o filósofo a "arte apresenta para a humanidade o sonho de 
sua derrocada para que ela desperte, torne-se senhora de si mesma e sobreviva" (ADORNO, 2021, p. 262-263).

\section{Referências}

ADORNO, Theodor W. Correspondência 1928-1940, Adorno - Benjamin. Trad. José Marcos Mariani de Macedo. São Paulo: Ed. Unesp, 2012.

ADORNO, Theodor W. Quasi una fantasia. Trad. Eduardo Socha. São Paulo: Ed. Unesp, 2018.

ADORNO, Theodor W. Sem diretriz - Parva aesthetica. Trad. Luciano Gatti. São Paulo: Ed. Unesp, 2021.

ADORNO, Theodor W. Towards a Theory of Music Reproduction. Trad. Wieland Hoban. Cambridge: Polity, 2006.

ARAÚJO, Bráulio Santos Rabelo de. O conceito de aura, de Walter Benjamin, e a Indústria Cultural. Pós. Revista do Programa de Pós-Graduação em Arquitetura e Urbanismo da FAUUSP, v.1, n.28, p. 120-143, 2010.

BENJAMIN, Walter. Escritos sobre Mito e Linguagem. Trad. Susana Kampff Lages e Ernani Chaves. São Paulo: Editora 34, 2011.

BENJAMIN, Walter. Magia e técnica, arte e política. Ensaios sobre literatura e história da cultura. Trad. Sergio Paulo Rouanet; Prefácio: Jeanne Marie Gagnebin. São Paulo: Brasiliense, 2012.

KOLISCH, Rudolf. How to Rehearse and Play Chamber Music (1940). MusikTheorie: Zeitschrift für Musikwissenschaft, v. 24, n. 3, p. 207-209, 2009.

KOLISCH, Rudolf. The Realization of Musical Meaning (1939). MusikTheorie: Zeitschrift für Musikwissenschaft, v. 24, n. 3, p. 201-207, 2009.

KUEHN, Frank Michael Carlos. A teoria da Reprodução Musical de Theodor Adorno e o legado da tradição vienense: uma introdução. Tese (Doutorado em Música) - Centro de Letras e Artes, Universidade Federal do Estado do Rio de Janeiro, Rio de Janeiro, 2010.

MARTINSON, Mattias. Music as Secularized Prayer. On Adornos Benjaminian Understanding. Comparative and Continental Philosophy, v. 10, n. 3, p. 205-220, 2018.

SCHOENBERG, Arnold. Fundamentos da Composição Musical. Trad. Eduardo Seincman. São Paulo: EDUSP, 1996.

SCHOENBERG, Arnold. Style and Idea. Los Angeles: University of California Press, 1984.

TRIPPETT, David. The Composer's Rainbow: Rudolf Kolisch and the Limits of Rationalization. MusikTheorie: Zeitschrift für Musikwissenschaft, v. 24, n. 3, p. 228-237, 2009. 
